\title{
An Empirical Assessment of Lognormality in Black- Scholes Option Pricing Model
}

\author{
Felix N. Nwobi ${ }^{1}$, Chukwudi A. Ugomma ${ }^{2}$ and Emmanuel U Ohaegbulem ${ }^{3}$ \\ ${ }^{123}$ Department of Statistics, Imo State University, Owerri, 460222, Nigeria \\ DOI: 10.29322/IJSRP.11.11.2021.p11950 \\ http://dx.doi.org/10.29322/IJSRP.11.11.2021.p11950
}

\begin{abstract}
This paper evaluates the lognormality assumption in Black-Scholes call options model. The data for this study were obtained from Australian Clearing House of Australian Securities Exchange (ASX). The data consists of fifty (50) enlisted stocks in the clearing house as products of monthly market summary for long term options which consists of the period of January 3rd, 2017 to December, 31 st 2019 when there are no significant structural changes among the products arranged in 25, 27, 28, 29 and 30 maturity days. The Jarque-Bera test was used to test for the normality of Black-Scholes call of different maturity days and we observed that the normality was rejected at $(\mathrm{p}<0.05)$. Further, normality test was also carried when the Black-Scholes options were log transformed and the normality test was rejected at $\mathrm{p}<0.05$. From the results of this study, the assumption of lognormality in Black-Scholes Option pricing model was violated.
\end{abstract}

Index Terms- Black-Scholes, lognormal, Normality Test, Option prices

\section{INTRODUCTION}

B lack - Scholes model is unarguably very popular among financial practitioners and researchers since its foundation by Fisher Black and Myron Scholes in 1973. Merton (1976) not only derived this model using alternative method but his approach generalized the Black - Scholes model. The model is a very important option pricing model in financial theory. The model provides a formula in which the determinants of option prices are fed and the final outcomes on the value of options are derived. Black - Scholes models are built upon Brownian motion which can be seen as a continuous time limit of random walks (Sprinkle, 1961; Black and Scholes, 1973). The Black-Scholes model has proved itself over time to be a rather popular subject of discuss. (see, for example, Chris (1997), Hull (1999), Taleb (1996) and Rachev, et al (2010)). Although, Black-Scholes model is an imperative tool for pricing options, it is built upon some non - real life assumptions about the market, which include: constant volatility, lognormality, constant interest rates, non - payment of dividends, no commission and transaction costs and European style of option

The key complexity to the Black - Scholes model is the use of cumulative normal probability function, $\phi(d)$. The function $\phi(d)$

is the probability that a standard normally distributed random variable will have a value equal to or less than the quantity of $d$. The model produces an option prices made from different five variables as $C\left(X_{t}, k, T, \sigma, r\right)$, defined as current price $X_{t}$, the strike/Exercise price, $K$, maturity time, $T$, option volatility, $\sigma$ and interest rate, $r$.

The Black - Scholes for Call and Put Option are given, respectively, as

$C_{t}\left(X_{t}, T\right)=\mathrm{X}_{0} \Phi\left(d_{1}\right)-\mathrm{K} e^{-r T} \Phi\left(d_{2}\right)$

and

$P(\mathrm{~K}, \mathrm{~T})=\mathrm{K} e^{-r T} \Phi\left(-d_{2}\right)-\mathrm{X}_{0} \Phi\left(-d_{1}\right)$

The quantities $d_{1}$ and $d_{2}$ can be obtained from a statistical table or from Excel Software.

Several authors have relaxed the lognormality assumption in Black-Scholes for the price of the underlying. For example, Jarrow and Rudd (1982) used the generalized Edgeworth expansion of the lognormal distribution of the asset price to obtain a model that corrects the Black-Scholes for the higher moments in underlying distribution. Black-Scholes assumes that asset prices follow a lognormal distribution based on the principle that the asset prices cannot take a negative value, that is, they are bounded by zero and that lognormal distribution is skewed to the right (it has no long right tail). These characteristics are in direct contrast to those of the normal distribution, which is symmetrical (zero or near zero skew) and can take on both negative and positive values. Consequently, the normal distribution cannot be used to model asset prices because the prices cannot fall below zero, hence the lognormal distribution (Hull,2002).

The assumption of lognormality has been criticized by several authors such as Clark (1973), Corrado and Su, (1996), Dutta and Babbel, (2002), Savickas, (2002); Teneng (2011), Jankora (2018) and Seth (2021), where they affirmed that asset returns have a finite 
variance and semi - heavy tails instead of stable distributions like lognormal with infinite variance and heavy - tails, meaning that sometimes asset returns may be leptokurtic.

The implication of lognormality assumption of Black-Scholes in real life is that stock prices never exhibit lognormal returns as assumed by Black-Scholes, hence, the real life distributions are either positively or negatively skewed. This inconsistency leads to the Black-Scholes model considerably underpricing or overpricing an option (Seth, 2021).

Hence, in this paper, we use the test of normality to assess empirically the effect of lognormal in the Black-Scholes call price of 50 enlisted stocks of Australian Securities Exchange (ASX) from 2017 to 2019.

\section{LOGNORMAL PROPERTY OF OPTION PRICES}

Let $X \in Z \sqcup N(0,1)$, then $Z=\ln (X)$ follows a lognormal distribution with parameters $\mu$ and $\sigma$, where $\sigma$ the shape parameter and $e^{\mu}$ is the scale parameter. The lognormal distribution has the following properties:

(i) Probability Density function of $X$ is given by

$f(X)=\frac{d}{d X} P\left(e^{Z}<X\right)=\frac{d}{d X} f_{Z}(\ln X)$
$=\frac{1}{X} f_{Z}(\ln X)=\frac{1}{\sqrt{2 \pi \sigma X}} \exp -\left\{\frac{(z-\mu)^{2}}{2 \sigma^{2}}\right\} \mathrm{dz}$

(ii) The cumulative distribution function is given by

$F(X)=\Phi \frac{(z-\mu)^{2}}{\sigma}, z \in(0, \infty)$

Now consider the $r$ th moment of $X$ as

$$
\begin{aligned}
& E\left(X^{r}\right)=\mathrm{E}\left(\mathrm{e}^{r z}\right)=\int_{-\infty}^{\infty} \mathrm{e}^{\mathrm{rz}} \frac{1}{\sigma \sqrt{2 \pi}} \exp -\left\{\frac{(z-\mu)^{2}}{2 \sigma^{2}}\right\} \mathrm{dz} \\
= & \frac{1}{\sigma \sqrt{2 \pi}} \int_{-\infty}^{\infty} \mathrm{e}^{\mathrm{rz}} \exp -\left\{\frac{(z-\mu)^{2}}{2 \sigma^{2}}\right\} \mathrm{dz}
\end{aligned}
$$

The value in the exponent in (5) is

$$
\frac{1}{2 \sigma^{2}}\left(-z^{2}-\mu^{2}+2\left(r \sigma^{2}+\mu\right) z\right)
$$

After completing the squares in $z$ of (6), and taking the absolute value $z^{2}$ positive, and then adding and subtracting $\left(r \sigma^{2}+\mu\right)^{2}$ to get

$$
-\frac{\left[z-\left(\mu+r \sigma^{2}\right)\right]^{2}}{2 \sigma^{2}}+\left(r \mu+r^{2} \frac{1}{2} \sigma^{2}\right)
$$

$E\left(X^{r}\right)=\exp -\left(r \mu+r^{2} \frac{1}{2} \sigma^{2}\right) \int_{-\infty}^{\infty} \frac{1}{\sigma \sqrt{2 \pi}} \exp -\left\{\frac{\left(z-\mu+r \sigma^{2}\right)}{2 \sigma^{2}}\right\} \mathrm{dz}$

where the expression in the integral equals unity, and as such

$$
E\left(X^{r}\right)=\exp -\left(r \mu+r^{2} \frac{1}{2} \sigma^{2}\right)
$$

Hence, the $r t h$ moment of the lognormal distribution is given by

$$
E(X)=\exp \left\{\mu+\frac{\sigma^{2}}{2}\right\}
$$


(ii)

(iii)

(iv)

$$
\operatorname{Var}(X)=\exp \left\{2 \mu+\sigma^{2}\right\} \exp \left[\left\{\sigma^{2}\right\}-1\right]
$$

It should be recalled that skewness and kurtosis do not depend on ${ }^{\mu}$ because $\mu_{\text {is a location parameter. The lognormal property }}$ of option prices can be used to provide information on the probability distribution of the continuously compounded rate of return, $r$, earned on option price at maturity time, T. This implies that interest is continuously been paid and each payment of interest itself is immediately being paid annual interest (Rachev, et al 2010). We define the continuously compounded rate of return, ${ }^{r}$, as:

$$
X_{t}=\mathrm{X}_{0} \exp \{-r T\}
$$

and

$\mathrm{r}=\frac{1}{\mathrm{~T}} \ln \left(\frac{K}{X_{0}}\right)$

where

$\mathrm{X}_{t}=$ The option (stock)

$\mathrm{X}_{0}$ is the current price of the underlying asset

$\mathrm{K}$ is the strike or exercise price

$\mathrm{T}$ is the maturity time of the option

Let the option price at $\mathrm{t}=0$ be equal to $\mathrm{X}_{0}$ (initial price) and at any time, $T$, in the future options. At expiration time, $T$, the Call is worth:

$C_{t}\left(X_{t}\right)=\left(X_{t}-K, 0\right)^{+}$

where the expression on the RHS of (13) is an abbreviated notation for the maximum of $X_{t}-K$ and 0 since $X_{t}>K$.

It should be recalled that option provides the buyer with the right but not the obligation to buy one unit of the option at time, ${ }^{t}$. Therefore, when the option price at time, ${ }_{t},{ }^{X_{t}}$ is not greater than $K$, the option is worthless because the buyer can buy one unit of the option for only $X_{t}$ on the market than to pay $K$, and, therefore, the option provides a worthless right in that case.

Suppose, we are interested in the value of the call option at some point in time proceeding to expiration, on the other hand, we do not know what the price will be, then, the whole terminal price for the option will be given as

$$
X_{\tau}=X_{0} \exp \left(-r-\frac{\sigma^{2}}{2}\right) T+\sigma \psi_{\tau}
$$

where $X_{t}$ is the option (stock) at time, $t ; t=1,2, N-1$ and $\psi_{\tau}$ is a $N\left(0, \sigma_{T}^{2}\right)$ random variable such that the exponent in (14) become a random variable with mean, $\left(r-\frac{\sigma^{2}}{2}\right) T$ and variance, $\sigma_{T}^{2}$. The exponent is referred to as the stock price dynamic and the parameter, $\sigma$, is known as the option price volatility. As a result, the price of the call option is given as

$C_{\tau}\left(X_{t}, K, T, r, \sigma^{2}\right)=r \exp (-r T) E\left(\left(X_{t}-K, 0\right)^{+}\right.$

$=\exp (-r T) \int_{-\infty}^{\infty}\left(X_{t}-K, 0\right)^{+} f\left(X_{t}\right) d X_{t}$

where $f(*)$ in (15) denotes the probability density function of $X_{t}$ evaluated at the result ${ }{ }_{t}$. The maximum operator in (15) can explicitly be computed as to obtain 
$C_{T}\left(X_{t}, K, T, r, \sigma^{2}\right)=0\left(r P\left\{X_{t} \leq K\right\}\right)+\exp (-r T) \int_{K}^{\infty}\left(X_{t}-K\right) f\left(X_{t}\right) d X_{t}$

The

integral of $\left(X_{t}-K\right)$ divided into two integrals of $X_{t}$ and $-K$, respectively, simplifies to

$\exp (-r T) \int_{K}^{\infty} X_{t} f\left(X_{t}\right) d X_{t}=\exp (-r T) K\left[\mathrm{p}\left(X_{t}>K\right)\right]$

The exponent in (16) is a normal varia
$\left(\frac{X_{t}}{X_{0}}\right) \square \ln \left(\left(r-\frac{\sigma^{2}}{2}\right) T, \sigma_{T}^{2}\right)$

To compute $P\left(X_{t}>K\right)$ in (16), let's consider that $X_{t}>K$ is exactly when $\frac{X_{t}}{X_{0}}>\frac{K}{X_{0}}$.

This again is equivalent to

$$
\ln \left(\frac{X_{t}}{X_{0}}\right)>\ln \left(\frac{K}{X_{0}}\right)
$$$$
\left(\frac{X_{t}}{X_{0}}\right)
$$

is normally distributed.

Therefore, the standardized random variable,

$P\left(X_{t}>K\right)=P\left(\frac{\ln \left(\frac{X_{t}}{X_{0}}\right)-\left(r-\frac{\sigma^{2}}{2}\right) T}{\sigma \sqrt{T}}>\frac{\ln \left(\frac{X_{0}}{K}\right)-\left(r-\frac{\sigma^{2}}{2}\right) T}{\sigma \sqrt{T}}\right)$

$X_{t}>K$, it consequently occurs with the probability obtained as

$P\left(X_{t}>K\right)=P\left(\frac{\ln \left(\frac{X_{t}}{X_{0}}\right)-\left(r-\frac{\sigma^{2}}{2}\right) T}{\sigma \sqrt{T}}>\frac{\ln \left(\frac{X_{0}}{K}\right)-\left(r-\frac{\sigma^{2}}{2}\right) T}{\sigma \sqrt{T}}\right)$

$=1-P\left(\frac{\ln \left(\frac{X_{t}}{X_{0}}\right)-\left(r-\frac{\sigma^{2}}{2}\right) T}{\sigma \sqrt{T}} \leq \frac{\ln \left(\frac{X_{0}}{K}\right)-\left(r-\frac{\sigma^{2}}{2}\right) T}{\sigma \sqrt{T}}\right)$

$=\phi\left(\frac{\ln \left(\frac{X_{0}}{K}\right)+\left(r-\frac{\sigma^{2}}{2}\right) T}{\sigma \sqrt{T}}\right)=\phi\left(d_{2}\right)$

We recall that $Y=\left(\frac{X_{t}}{X_{0}}\right)$ is lognormally distributed, and can also be expressed as $X_{t}=Y X_{0}$ by $f_{X}\left(X_{t}\right)=f_{Y}\left(\frac{X_{t}}{X_{0}}\right)\left(\frac{1}{X_{0}}\right)$ so that the integral in (16) changes to 


$$
\int_{K}^{\infty} X_{t} f_{x}\left(X_{t}\right) d X_{t}=\int_{K}^{\infty} X_{t} f_{Y}\left(\frac{X_{t}}{X_{0}}\right)\left(\frac{1}{X_{0}}\right) d X_{t}=\int_{\left(\frac{K}{X_{0}}\right)}^{\infty} X_{0} y f_{Y}(y) d y
$$

Due to the lognormal distribution, the integral in (18) is further expressed as

$$
\int_{K}^{\infty} X_{t} d X_{t}=\int_{\left(\frac{K}{X_{0}}\right)}^{\infty}\left(\frac{X_{0} y}{\sqrt{2 \pi \sigma^{2} T y}}\right) \exp \left(-\frac{\ln y-\left(r-\frac{\sigma^{2}}{2}\right) T}{2 \sigma^{2} T}\right)^{2} d y
$$

Let $Z=\ln Y$ be another random variable, then,

$$
\begin{aligned}
& \int_{K}^{\infty} X_{t} d X_{t}=X_{0} \int_{\left(\frac{K}{X_{0}}\right)}^{\infty}\left(\frac{1}{\sqrt{2 \pi \sigma^{2} T}}\right) \exp \left(-\frac{\ln y-\left(r-\frac{\sigma^{2}}{2}\right) T}{2 \sigma^{2} T}\right)^{2} \exp (-z) d z \\
& =X_{0} \int_{\ln \left(\frac{K}{X_{0}}\right)}^{\infty}\left(\frac{1}{\sqrt{2 \pi \sigma^{2} T}}\right) \exp \left(-\frac{-\left(Z-\left(r-\frac{\sigma^{2}}{2}\right) T\right)^{2}-2 \sigma^{2} T z d z}{2 \sigma^{2} T}\right)
\end{aligned}
$$

Equation (9) can further be simplified as

$$
-\frac{\left(z-\left(r-\frac{\sigma^{2}}{2}\right) T\right)^{2}-2 \sigma^{2} T z}{2 \sigma^{2} \pi T}=-\frac{\left(z-\left(r+\frac{\sigma^{2}}{2}\right) T\right)^{2}}{2 \sigma^{2} \pi T}+r T
$$

Substituting (20) into (19), we obtain

$$
\begin{aligned}
& \int_{K}^{\infty} X f_{X}\left(X_{t}\right) d X_{t}=X_{0} \exp (-r T) \int_{\ln \left(\frac{K}{X_{0}}\right)}^{\infty}\left(\frac{1}{\sqrt{2 \pi \sigma^{2} T}}\right)-\left(Z-\left(r-\frac{\sigma^{2}}{2}\right) T\right)^{2} d z \\
& \qquad P\left(Z>\ln \left(\frac{X_{0}}{K}\right)\right)_{\text {of some norm }}
\end{aligned}
$$$$
\left(r+\frac{\sigma^{2}}{2}\right) T \text { and variance, } \sigma^{2} T
$$

Therefore, through standardization of $Z$, equation (21) becomes

$$
\int_{K}^{\infty} X f_{X}\left(X_{t}\right) d X_{t}=X_{0} \exp (-r T) P \frac{\left(Z>\ln \left(\frac{X_{0}}{K}\right)-\left(r+\frac{\sigma^{2}}{2}\right) T\right)}{\sigma \sqrt{T}}
$$

Substituting (17) into (21), and (19), and multiplying both sides by $e^{-r t}$ we obtain the famous Black - Scholes pricing model for European Call 
$C_{B S}=e^{-r T}\left[X_{0} \Phi \frac{\left(\ln \left(\frac{X_{0}}{K}\right)+\left(r+\frac{\sigma^{2}}{2}\right) T\right)}{\sigma \sqrt{T}}-K e^{-r T} \Phi \frac{\left(\ln \left(\frac{X_{0}}{K}\right)+\left(r-\frac{\sigma^{2}}{2}\right) T\right)}{\sigma \sqrt{T}}\right]$

Hence,

$C_{B S}=X_{0} \Phi\left(d_{1}\right)-K e^{-r T} \Phi\left(d_{2}\right)$

Where,

$d_{1}=\frac{\left(\ln \left(\frac{X_{0}}{K}\right)+\left(r+\frac{\sigma^{2}}{2}\right) T\right)}{\sigma \sqrt{T}}$

$d_{2}=\frac{\left(\ln \left(\frac{X_{0}}{K}\right)+\left(r-\frac{\sigma^{2}}{2}\right) T\right)}{\sigma \sqrt{T}}$

Similarly, a European Put Option can be derived as

$$
\begin{gathered}
P_{B S}=\frac{\Phi\left(-d_{2}\right)\left(K-X_{0} e^{-r T} \Phi\left(-d_{1}\right)\right)}{\Phi\left(-d_{2}\right)} \\
P_{B S}=K e^{-r T} \Phi\left(-d_{2}\right)-X_{0} \Phi\left(-d_{1}\right)
\end{gathered}
$$

\section{DATA DESCRIPTION AND METHOD OF ANALYSIS}

\subsection{Data Description}

The data for this study were obtained from Australian Clearing House of Australian Securities Exchange (ASX). The sample consists of fifty (50) enlisted stocks in the clearing house as products of monthly market summaries for long term options which consists of the period of January, $3^{\text {rd }} 2017$ to December, $31^{\text {st }} 2019$ when there are no significant structural changes among the products. For each transaction, our sample contains the following information: the opening and closing dates of the options, option prices comprising opening and closing prices otherwise referred in our case as the underlying and strike prices respectively. The final sample consists of 50 stocks for the period of 36 months (720 trading days).

The maturity period of the options was gotten from the difference between the opening date and closing date of the options over the trading days. The data for the analysis obtained from http//www.asx.com/au/product/equity_options/options_statistics.htm were arranged in accordance to the maturity days of 25, 27, 28, 29 and 30 days.

\subsection{Methodology}

The data in each of the maturity days (expiration time) were tested according to weekly, monthly and yearly where the trading days were divided by 6,24 and 252 respectively.

To check for the log normality assumption in Black-Scholes option pricing model, the predicted Black-Scholes model in each of the expiration time were firstly tested for normality and if the model follows normal, it is log transformed and further conduct a test for normality.

The Computation of the Annualized Standard Deviation (Implied Volatility) is illustrated as follows:

Let $\mathrm{X}_{i}=\ln \left(\frac{\mathrm{X}_{\mathrm{t}}}{\mathrm{X}_{\mathrm{t}-1}}\right), X_{t}$ is the underlying option price at time $\mathrm{t}$.

$\bar{x}=\frac{1}{n} \sum_{i=1}^{n} x_{i} \quad \sigma_{X}^{2}=\frac{1}{n-1} \sum_{i=1}^{n}\left(x_{i}-\bar{x}\right)^{2}$

So that the implied volatility is obtained by

$\hat{\sigma}_{i m}=\sqrt{\frac{\sigma_{x}^{2}}{\Delta t}} \quad$ where, $\Delta t=t_{i}, t_{i-1}, .$. 
$=\sqrt{\frac{T}{n} \frac{1}{n-1} \sum_{i=1}^{n}\left(x_{i}-\bar{x}\right)^{2}}$

and the rate of return is estimated by

$r=\frac{1}{T} \ln \left(\frac{k}{X_{0}}\right)$

IV. EMPIRICAL EVIDENCE

Table 1: Summary Statistics of ASX Original Data

\begin{tabular}{|c|c|c|c|c|c|c|}
\hline $\begin{array}{l}\text { Maturit } \\
\text { y Days }\end{array}$ & $\begin{array}{l}\text { Sampl } \\
\text { e Size }\end{array}$ & $\begin{array}{l}\text { Sample } \\
\text { Mean } \\
(\bar{X})\end{array}$ & $\begin{array}{l}\text { Sample } \\
\text { Variance } \\
\left(S^{2}\right)\end{array}$ & $\begin{array}{l}\text { Skewness } \\
\text { Skew }(X)\end{array}$ & $\begin{array}{l}\text { Kurtosis } \\
\operatorname{Kurt}(X)\end{array}$ & $\begin{array}{l}\text { Implied } \\
\text { Volatility } \\
\left(\bar{\sigma}_{i m}\right)\end{array}$ \\
\hline 25 & 99 & $\begin{array}{l}- \\
0.0034 \\
0 \\
-\end{array}$ & 2.55 & 0.57 & 1.36 & 2.55 \\
\hline 27 & 199 & $\begin{array}{l}0.0019 \\
0 \\
-\end{array}$ & 2.65 & 0.56 & 1.32 & 1.74 \\
\hline 28 & 399 & $\begin{array}{l}0.0009 \\
2 \\
-\end{array}$ & 2.70 & 0.55 & 0.99 & 1.31 \\
\hline 29 & 449 & $\begin{array}{l}0.0005 \\
3 \\
-\end{array}$ & 2.83 & 0.56 & 1.19 & 1.26 \\
\hline 30 & 499 & $\begin{array}{l}0.0005 \\
7\end{array}$ & 2.74 & 0.56 & 1.04 & 1.18 \\
\hline
\end{tabular}

The result from Table 1 showed normality since the skewness from the various maturity days are positive meaning that the right tail of the distribution is longer than the left and their kurtosis also suggested that the distribution is perfectly peaked. The result indicated that the options from ASX is normally distributed.

Table 2: Summary Statistics of Lognormal Distribution Parameters

\begin{tabular}{llllllll}
\hline $\begin{array}{l}\text { Maturity } \\
\text { Days }\end{array}$ & $\begin{array}{l}\text { Sample } \\
\text { Size }\end{array}$ & $\begin{array}{l}\text { Sample } \\
\text { Mean } \\
(\bar{X})\end{array}$ & $\begin{array}{l}\text { Sample } \\
\text { Variance } \\
\left(S^{2}\right)\end{array}$ & $\begin{array}{l}\text { Mean } \\
E\left(X_{L}\right)\end{array}$ & $\begin{array}{l}\text { Std. Dev. } \\
\sigma_{\left(X_{L}\right)}\end{array}$ & $\begin{array}{c}\text { Skewness } \\
\operatorname{Skew}\left(X_{L}\right)\end{array}$ & $\begin{array}{c}\text { Kurtosis } \\
\text { Kurt }\left(X_{L}\right)\end{array}$ \\
\hline 25 & 99 & -0.0034 & 2.55 & 3.59 & 0.3704 & 0.1136 & 1.9130 \\
27 & 199 & -0.0019 & 2.65 & 3.77 & 0.3693 & 0.0842 & 2.1141 \\
28 & 399 & -0.00092 & 2.70 & 3.86 & 0.3686 & 0.0781 & 2.2225 \\
29 & 449 & -0.00053 & 2.83 & 4.12 & 0.3683 & 0.0642 & 2.5310 \\
30 & 499 & -0.00057 & 2.74 & 3.94 & 0.3683 & 0.0735 & 2.3132 \\
\hline
\end{tabular}

From Table 2, the result showed that the skewness for all maturity days were also positive and somewhat approximately zero indicating positive perfect symmetry. Their kurtosis are above +1 indicating too peaked distribution. This means that options for ASX is leptokurtic in nature. 
Table 3: The Implied Volatilities for different maturity days according to trading days

\begin{tabular}{llll}
\hline \multirow{2}{*}{ Maturity Days } & \multicolumn{3}{l}{ Volatilities according to trading days } \\
\cline { 2 - 4 } & Weekly (6) & Monthly (24) & Yearly (24) \\
\hline 25 & 0.39 & 0.78 & 2.54 \\
27 & 0.47 & 0.95 & 3.08 \\
28 & 0.33 & 0.67 & 2.16 \\
29 & 0.31 & 0.62 & 2.02 \\
30 & 0.30 & 0.61 & 1.97 \\
\hline
\end{tabular}

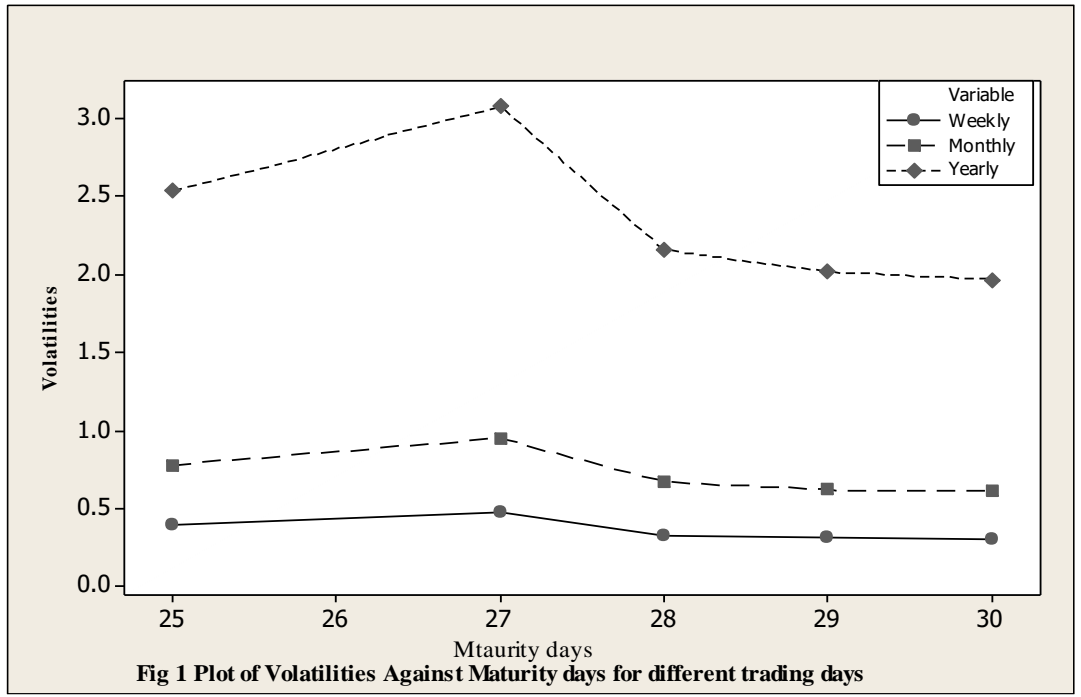

Since volatility significantly affects the option prices, meaning the higher volatility of the underlying asset; the higher is the price for both call and put options. We observed from figure 1 that there is low volatility when options are traded weekly at the rate of 47 percent, increased significantly when the options were traded monthly at the rate of 95 percent especially at maturity days of 27 . The implied volatility increased higher when the options are traded yearly (i.e., 252 trading days). We observed that more trading days significantly increased the implied volatility at about 300 percent observed also at maturity days of 27, thereby resulting in high priced option prices at 27 maturity days for all the trading days.

Table 4: Normality Test for Black-Scholes Calls for different maturity days according to trading days

\begin{tabular}{|c|c|c|c|c|c|c|c|c|c|}
\hline $\begin{array}{l}\text { Trading } \\
\text { days }\end{array}$ & $\begin{array}{l}\text { Siz } \\
\mathrm{e}\end{array}$ & $\begin{array}{l}\text { Maturity } \\
\text { Days }\end{array}$ & Mean & $\begin{array}{l}\text { Std. } \\
\text { Dev. }\end{array}$ & $\begin{array}{l}\text { Skewnes } \\
\text { s }\end{array}$ & Kurtosis & JB Stat & P-Value & Decision \\
\hline & 99 & 25 & 18.46 & 30.78 & 4.38 & 24.23 & $\begin{array}{l}2176.3 \\
2\end{array}$ & 0.0000 & Reject \\
\hline \multirow[t]{5}{*}{6} & 199 & 27 & 17.56 & 24.35 & 3.08 & 11.24 & 877.81 & 0.0000 & Reject \\
\hline & 399 & 28 & 18.88 & 29.40 & 4.01 & 21.40 & $\begin{array}{l}6698.4 \\
3\end{array}$ & 0.0000 & Reject \\
\hline & 449 & 29 & 21.19 & 31.72 & 3.75 & 18.89 & $\begin{array}{l}5776.0 \\
9\end{array}$ & 0.0000 & Reject \\
\hline & 499 & 30 & 19.75 & 31.03 & 3.71 & 16.90 & $\begin{array}{l}5166.1 \\
9\end{array}$ & 0.0000 & Reject \\
\hline & 99 & 25 & 20.84 & 32.01 & 3.90 & 19.71 & $\begin{array}{l}1403.0 \\
4\end{array}$ & 0.0000 & Reject \\
\hline \multirow[t]{3}{*}{24} & 199 & 27 & 20.39 & 28.44 & 3.06 & 11.28 & 879.65 & 0.0000 & Reject \\
\hline & 399 & 28 & 20.87 & 30.67 & 3.73 & 18.77 & $\begin{array}{l}5059.4 \\
5\end{array}$ & 0.0000 & Reject \\
\hline & 449 & 29 & 21.82 & 32.92 & 3.66 & 17.40 & $\begin{array}{l}4882.6 \\
7\end{array}$ & 0.0000 & Reject \\
\hline
\end{tabular}




\begin{tabular}{|c|c|c|c|c|c|c|c|c|c|}
\hline & 499 & 30 & 21.42 & 31.97 & 3.49 & 14.90 & $\begin{array}{l}3958.7 \\
5\end{array}$ & 0.0000 & Reject \\
\hline & 99 & 25 & 21.14 & 32.24 & 3.84 & 19.07 & $\begin{array}{l}1308.7 \\
2\end{array}$ & 0.0000 & Reject \\
\hline \multirow[t]{4}{*}{252} & 199 & 27 & 20.48 & 28.61 & 3.08 & 11.48 & 910.42 & 0.0000 & Reject \\
\hline & 399 & 28 & 21.37 & 31.21 & 3.67 & 18.13 & $\begin{array}{l}4703.7 \\
2\end{array}$ & 0.0000 & Reject \\
\hline & 449 & 29 & 21.86 & 32.97 & 3.65 & 17.30 & $\begin{array}{l}4825.7 \\
3\end{array}$ & 0.0000 & Reject \\
\hline & 499 & 30 & 21.95 & 32.53 & 3.42 & 14.18 & $\begin{array}{l}3569.3 \\
2\end{array}$ & 0.0000 & Reject \\
\hline
\end{tabular}

The null hypothesis that Black-Scholes Call Option prices follow a lognormal distribution was clearly rejected since the p-value of Jarque-Bera test is significant. Comparing the Jarque-Bera test of normality at 0.05 level of significance, we observed that the null hypothesis for all the maturity and trading days of ASX data violated the assumption of lognormality of Black-Scholes option pricing as claimed by Black and Scholes (1973).

Table 4: Normality Test for log of Black-Scholes Calls for different maturity days according to trading days

\begin{tabular}{llllllllll}
\hline $\begin{array}{l}\text { Trading } \\
\text { days }\end{array}$ & Size & $\begin{array}{l}\text { Maturit } \\
\text { y Days }\end{array}$ & Mean & $\begin{array}{l}\text { Std. } \\
\text { Dev. }\end{array}$ & $\begin{array}{l}\text { Skewnes } \\
\text { s }\end{array}$ & $\begin{array}{l}\text { Kurtosi } \\
\text { s }\end{array}$ & JB Stat & P-Value & Decision \\
\hline \multirow{6}{*}{6} & 99 & 25 & 0.9674 & 0.4916 & 0.22 & 0.41 & 28.51 & 0.0000 & Reject \\
& 199 & 27 & 0.9571 & 0.5224 & -0.38 & 1.36 & 27.30 & 0.0000 & Reject \\
& 399 & 28 & 0.9749 & 0.5123 & -0.09 & 0.78 & 82.75 & 0.0000 & Reject \\
& 449 & 29 & 1.028 & 0.5205 & -0.26 & 1.12 & 70.90 & 0.0000 & Reject \\
& 499 & 30 & 0.9746 & 0.5404 & -0.25 & 0.99 & 89.14 & 0.0000 & Reject \\
\hline \multirow{6}{*}{24} & 99 & 25 & 1.031 & 0.4903 & 0.16 & 0.33 & 29.76 & 0.0000 & Reject \\
& 199 & 27 & 1.029 & 0.4980 & -0.05 & 0.44 & 54.60 & 0.0000 & Reject \\
& 399 & 28 & 1.034 & 0.4988 & -0.01 & 0.33 & 118.65 & 0.0000 & Reject \\
& 449 & 29 & 1.041 & 0.5097 & -0.04 & 0.48 & 119.22 & 0.0000 & Reject \\
& 499 & 30 & 1.034 & 0.5094 & -0.00 & 0.34 & 146.93 & 0.0000 & Reject \\
\hline \multirow{6}{*}{252} & 99 & 25 & 1.037 & 0.4913 & 0.16 & 0.32 & 30.01 & 0.0000 & Reject \\
& 199 & 27 & 1.031 & 0.4981 & -0.04 & 0.43 & 54.65 & 0.0000 & Reject \\
& 399 & 28 & 1.044 & 0.4990 & -0.01 & 0.30 & 121.44 & 0.0000 & Reject \\
& 449 & 29 & 1.042 & 0.5085 & -0.02 & 0.43 & 123.31 & 0.0000 & Reject \\
& 499 & 30 & 1.034 & 0.5074 & -0.00 & 0.34 & 153.61 & 0.0000 & Reject \\
\hline
\end{tabular}

The log transformation of the Black-Scholes Call Option prices was also tested based on the null hypothesis that the log of the Black-Scholes prices also follow a lognormal distribution was clearly rejected since the p-value of Jarque-Bera test is significant ( $p<$ 0.05). Comparing the Jarque-Bera test of normality at 0.05 level of significance, we observed that the null hypothesis for all the maturity and trading days of ASX data also failed the assumption of lognormality.

\section{CONCLUSION}

In this paper, we observed that the option prices collected from Australian Clearing House of Australian Securities Exchange (ASX) failed the test of lognormality in all the maturity days using Jarque-Bera test of normality. Hence, we conclude that Black-Scholes Call Option prices violated the assumption that stock prices follow a lognormal distribution as presumed by Black-Scholes of 1973.

\section{REFERENCES}

[1] Black, F and Scholes, M (1973): The Pricing of Options and Corporate Liabilities. The Journal of political Economy. 8(3).

[2] Chris, N.A. (1997): Black-Scholes and Beyond. McGraw-Hill, New York.

[3] Clark, P.B (1973): Uncertainty, Exchange Risk and the level of International Trade. Western Economic Journals, 11:302 - 313.

[4] Corrado, C.J and Su, T (1996): Skewness and Kurtosis in S\&P 500 Index Returns Implied by Option prices. Journal of Financial Research. 19 (2), 175 - 192.

[5] Dutta, K.K and Babbel, D.F (2002): Extracting Probabilistic Information from the prices of Interest Rate Options: Tests of Distributional Assumptions. Wharton Institutions Centre. The Wharton University of Pennsylvania, working paper, NERA.

[6] Hull, J.C. (2002): Options Futures and other Derivatives. 7th Edition. Prentice Hall. 
[7] Jankora, Z (2018). Drawbacks and Limitations of Black-Scholes Model for Options Pricing. Journal of Financial Studies and Research.

[8] Jarrow, R and Rudd, A. (1982): Approximate Option Valuation for Arbitrage Stochastic Processes, Journal of Financial Economics 10, 347 - 69.

[9] Merton, R (1976): Option Pricing when underlying Stocks Returns are Discontinuous. Journal of Political Economy, 3 (1 - 2), 125 - 144.

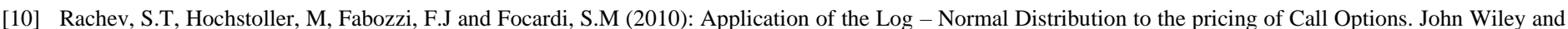
Sons, INC.

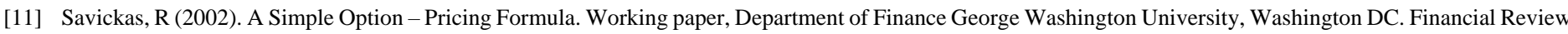
37(2) $207-226$.

[12] Seth, S (2021). Circumventing the Limitations of Black-Scholes, https//www.investopedia.com

[13] Sprinkle, C (1961): Warrant Prices as Indications of Expectations. Yale Economic Essays, 1:179 - 232.

[14] Taleb, N (1996). Dynamic Hedging, Managing Vanilla and Exotic Options. John Wiley \&Sons. Inc.

[15] Teneng, D (2011). Limitations of the Black-Scholes Model. International Research Journal of Finance and Economics, 99 - 102.

\section{AUTHORS}

First Author - Felix N. Nwobi, Department of Statistics, Imo State University, Owerri, 460222, Nigeria, fnnwobi@imsu.edu.ng Second Author - Chukwudi A. Ugomma, Department of Statistics, Imo State University, Owerri, 460222, Nigeria, chukwudiugomma@gmail.com

Third Author - Emmanuel U Ohaegbulem, Department of Statistics, Imo State University, Owerri, 460222, Nigeria, emmanx2002@yahoo.com

Correspondence Author - Chukwudi A. Ugomma., Department of Statistics, Imo State University, Owerri, Nigeria, Email: chukwudiugomma@gmail.com 